\title{
A high number of diseases and consultations: a warning signal for GPs when following up a multimorbid patient
}

Paul Aujoulat ( $\sim$ aujoulat.paul@yahoo.com )

Universite de Bretagne Occidentale https://orcid.org/0000-0002-4760-224X

Patrice NABBE

Universite de Bretagne Occidentale

Sophie LALANDE

Universite de Bretagne Occidentale

Delphine LE GOFF

Universite de Bretagne Occidentale

Jeremy DERRIENIC

Universite de Bretagne Occidentale

Jeanlin VIALA

Universite de Bretagne Occidentale

Jerome FONSECA

Universite de Bretagne Occidentale

Florence GATINEAU

Universite de Bretagne Occidentale

Jean Yves LE RESTE

Universite de Bretagne Occidentale

Research article

Keywords: multimorbidity, family medicine, decompensation, chronic condition, health care consumption

Posted Date: August 28th, 2019

DOl: https://doi.org/10.21203/rs.2.13278/v1

License: (c) (i) This work is licensed under a Creative Commons Attribution 4.0 International License.

Read Full License 


\section{Abstract}

Background: the European General Practitioners Research Network (EGPRN) designed and validated a comprehensive definition of multimorbidity using a systematic literature review and qualitative research throughout Europe. Detecting risk factors for decompensation would be an interesting challenge for family physicians (FPs) in the management of multimorbid patients. The purpose of the survey was to assess which items belonging to the EGPRN multimorbidity definition could help to identify patients at risk of decompensation in a cohort pilot study over a 24-month follow-up among primary care outpatients. Method : 131 patients meeting the multimorbidity definition were included using two inclusion periods between 2014 and 2015. Over a 24-month follow-up, the " decompensation » or " nothing to report » status was collected. A logistic regression, following a Cox model, was then performed to identify risk factors for decompensation. Results : After 24 months of follow-up, 120 patients were analyzed. 3 clusters were identified. 44 patients, representing $36.6 \%$ of the population, were still alive and had not been hospitalized for a period exceeding 6 days. Two variables were significantly linked to decompensation: the number of visits to the FP per year (HR 1.06, IC $95 \%, 1,03-1,10$, p-value <0,001) and the total number of diseases (HR 1,12, IC $95 \%, 1,013-1,33$, p-value $=0,039$ ). Conclusion: FPs should be aware that a high number of consultations and a high total number of diseases are linked to severe outcomes such as death or unplanned hospitalization. A large-scale cohort in primary care seems feasible to confirm these results.

\section{Background}

Due to advances in medical care and public health policies, an aging population brings with it an increasing rate of chronic disorders that interfere with many other disorders. The consequences are an increase in the burden of disease (1) (2)and in health systems' expenditure (3).

Thus, in 1976, the concept of multimorbidity was published for the first time (4). According to the World Health Organization (WHO), multimorbidity is defined as « people being affected by two or more chronic health conditions» (5).

This definition was subject to several criticisms, mainly because of the word " condition " that led to several interpretations, and many attempts to refine that definition were ineffective (6) (7) (8). Peculiarly, this definition failed to determine which items were suitable for the prevention of severe issues or were useful for handling multimorbidity in primary care consultations (9) (10).

However, Family Physicians (FPs), who are the first port of call in the care of multimorbid patients, were very interested in this challenging concept as it is closely related to a global view of the patient which is a basic skill of Family Medicine (FM) (11) (12). This concept particularly fits the competences field of Family Medicine, as defined by the World Organization of National Colleges, Academies and Academic Associations of General Practitioners/Family Physicians (WONCA) (13). Adding another string to the bow 
in investigating the complexity of patient conditions was an exciting project that could improve GPs' ability to detect a patient's frailty and to prevent severe outcomes such as hospitalization or death.

The concept of multimorbidity had stirred up some interest in the research agenda of the European General Practitioners Research Network (EGPRN)(14).

A research team which included 9 European countries, all involved in the European General Practitioners Research Network (EGPRN), aimed to clarify the concept of multimorbidity(15). In 2012, the EGPRN presented a comprehensive definition of multimorbidity in family medicine and long-term care.(16) It was the first attempt to define multimorbidity which benefited from the FP's pragmatic point of view (17). According to the EGPRN, multimorbidity is defined as « any combination of chronic disease with at least one other disease (acute or chronic) or psychosocial factor (associated or not) or somatic risk factor, any bio-psychosocial factor, any somatic risk factor, the social network, the burden of diseases, the health care consumption and the patient's coping strategies may function as modifiers (of the effects of Multimorbidity). Multimorbidity modifies the health outcomes and leads to increased disability or a decreased quality of life or frailty. » Thirteen themes have been outlined and then translated into ten European languages with the intention of inducing and standardizing further collaborative studies (18).

Nevertheless, that exhaustive definition covers too large a part of the population which renders it ineffective as it reduces the opportunity to pinpoint a patient at risk of severe outcomes. Since preventing acute hospitalization or death is a major concern of FM, (19) the EGPRN considered how to determine which variables within the concept would be effective in preventing those two events (20).

As FPs are very familiar with their patient's health status, (21) there could be some factors that might be neglected but which could help to avoid severe outcomes if they were noticed in time (22).

If the EGPRN could succeed in highlighting those variables, they could be integrated within the FPs' medical software and be a powerful tool in the care of multimorbid patients (23).

Consequently, a feasibility pilot cohort study was started in 2014 which included patients who met the EGPRN multimorbidity definition (24). Data were analysed every three months.

The main objective of this study was to assess which criteria, within the EGPRN concept of multimorbidity, could identify multimorbid patients at risk of decompensation in a primary care cohort in France over a 24-month follow-up.

\section{Methods}

\section{Ethic statement}

The study was approved by the ethics committee of the « Université de Bretagne Occidentale » Faculty of Medicine, Brest. The participants had to sign a written informed consent to participate in the study. The Family Physicians involved provided a verbal consent. 


\section{Participant selection}

The recruitment was handled by 31 FPs in western Brittany, France, who agreed to participate in the study after being contacted at their office. All were chosen from the Clinical Teacher list of Brest University.

All patients met the EGPRN definition of multimorbidity. 96 patients were included by 19 FPs between July and December 2014. 12 other FPs enrolled 35 new patients from September to November 2015 to increase the study's power.

Inclusion criteria were: having a chronic disease, with at least one other disease (acute or chronic) or a biopsychosocial factor (associated or not) or a somatic risk factor.

Biopsychosocial risk, including all psychological risk factors, psychosocial risk factors, lifestyle, demographic data (age, gender), psychological distress, socio-demographic characteristics, aging, beliefs and expectations of patients, physiology and pathophysiology were taken into account.

Each patient was monitored over time and had to sign an informed consent.

Exclusion criteria: patients not meeting the criteria of the multimorbidity definition, patients living in a nursing home, patients who were unable to follow the study over time, patients under legal protection, and patients whose condition was already life-threateningor whose life expectancy was estimated at less than three months.

\section{Data collection}

Each FP had to follow a plan: at the first stage, the multimorbid patient was given full information on the study by the FP and asked to give his/her consent.

Then, the FPs had to fill in a questionnaire to explore the potential decompensation risk factors within themes and subthemes of multimorbidity. (Table 1)

The questionnaire was designed by the research group with reference to the definition of multimorbidity. There were 52 questions, covering every item of the definition and based on a clinical and anamnestic approach by the FP. First, there were 7 questions about the patient's diseases. Then, there were 8 questions to evaluate the somatic risks factors. Questions 16 to 19 focused on the psychosocial factors, social network and coping strategies (defined as: diet and lifestyle, planning, instrumental support, social support, expression of feelings, positive reinstatement, acceptance, denying, blaming, sense of humor, religion, leisure activities, substance use). From Question 20 to Question 37, the FPs were asked about burden of diseases and health care consumption. There were then 4 questions about prevention vaccination and screening. The last questions pondered the core competencies of the FP and his/her relationship with his/her patient. 
The questionnaire is fully available (Appendix 1) as it was given to the FPs (in the French language).

From the first pilot study, some irrelevant variables were deleted for different reasons:

- Chronic condition redundancy with chronic disease or psychological risk factor)

- Cost of care (impossible to estimate given the time and resources dedicated to the study)

- Disability (disability / impairment, qualitiy of life and health outcomes (consequences rather than the characteristics of the multimorbidity)

- frailty (absence of consensual definition, criterion assessed by study, methodologically impossible to assess at the beginning of the study)

- physiology (too broad a notion, impossible to evaluate)

- disease and assessment (present in the theoretical definition but missing from the coding book and not found in the transcripts)

- demography and aging (redundant with sociodemographic characteristics)

Somatic risks were evaluated as cardiovascular risk factor, risk of falling factors (calculated with the CETAF score) (25), an assessment of hygiene, nutrition and physical activity at the discretion of the FP.

This questionnaire was accepted by the scientific committee of the research team and tested with FPs and medical students.

Thanks to the comments made during the first pilot study, a revised questionnaire was used for those patients included from September to November 2015. The question order was actually rearranged to ease and shorten the time needed to complete it. No question could be asked before the previous one had been answered in order to avoid omitting data. The FP was only asked question number 40 if he/she had answered "yes » to organized or individual screening in question number 39 to avoid errors in completion identifed in previous studies.

Data were saved using Microsoft Excel and computed by the online survey software EVA-LANDGO ${ }^{\circledR}$.

24 months after inclusion, FPs were contacted by email or phone (INSERER APPENDIX 5) to collect patient status information. Two types of status were defined after a consensus had been reached in a peer group gathering on multimorbidity made up of physicians, residential students and researchers in family practice: « decompensation » (D) and « Nothing to Report » (NTR). Decompensation was understood as the occurrence of hospitalization of at least 7 days duration, or death, during the 24 months of follow-up, as the mean duration for hospitalization in the European Union is 6.7 days (26).

Groups labelled « frail » or « not frail » in the feasibility study were changed at the six-month follow-up as confusion between « frail » and « frailty » might occur and this would include a definition which was not 


\section{Data analysis}

Data cleaning was performed to harmonize data for analysis. The ICD 10 was used to standardize the mentioned chronic diseases. 102 chronic diseases were reported.

Missing data were spotted during descriptive statistics analysis. They were replaced by the median value to be incorporated into the statistical analysis.

Each modification and the reasons for it were compiled in the « dictionary » available on demand from the corresponding author.

A description of the population was the first step. Both types of status « decompensation » and " nothing to Report » were compared using a bi-dimensional analysis for each variable.

Quantitative variables were compared using a Fischer's exact test or a chi-2 test with an alpha level set at $5 \%$. Qualitative variables were compared using a Student's test when it followed a normal distribution to compare the means of the two groups from a normal population, and a Shapiro-Wilk's test when it did not follow a normal distribution, to compare the medians of the two groups.

Patients with the same characteristics. regardless of status " Decompensation » or " Nothing to Report », were grouped together using a multidimensional analysis. Non-discriminating and non-descriptive variables were removed. Then, a clustering represented in a dendrogram and a multiple correspondence analysis (MCA) were performedto identify discriminating variables for each group and the resulting information was combined using the technique of hierarchical clustering on principal components (HCPC).

The second step comprised a statistical analysis of the follow-up. A logistic regression was used for the six and nine-month follow-up as the dependent variable was binary (D versus NTR), regardless of followup time. A Cox model was chosen to complete the analysis from the twelve-month study, making it possible to apply different durations of follow-up time to support each patient.The aim was to find the best subgroup of variables for predicting and explaining the patient's status at 24 months.

At first, the overall survival of the two populations for each variable were compared using a nonparametric estimator by Kaplan-Meier, with a Wilcoxon test of alpha-risk at $5 \%$. Then, the team estimated the survival function using semi-parametric models. A Hazard Ratio (HR) was first obtained by a univariate analysis using Cox's Model. Then, an adjusted HR was obtained with a multivariate analysis using Cox's model, representing the association between a variable and the decompensation risk factor.

\section{Results}




\section{Sample participants}

137 patients were included by 31 FPs. Out of the 137 patients, 6 were excluded for failing to complete questionnaires or for duplicate questionnaires. The status at 24 months was collected for all 131 patients. 11 were lost in follow-up because of a change of FP or because the FP ceased working. (Figure 1)

\section{Data cleaning and recoding}

Some variables were removed from data analysis because they were:

- not discriminating: divorce, use of pharmacological treatment, neglect of the patient, patient victim of iatrogeny, nursing home, lack of entourage

- of no use: identification number, inclusion date, date of birth (expressed as age)

- Irrelevant for the objective (referring to FPs feelings): variables related to quality of care, detection of multimorbidity and doctor self-assessment, detailed and/or complex medical history.

The recoding data work was transcribed in a dictionary (available on demand from the corresponding author).

\section{Characteristics of the patients included}

A cluster dendrogram was summarized from a hierarchical ascending classification (FIGURE 2). Inertia gain determined the number of clusters and, thanks to the clustering quality index, three groups were retained. The MCA factor map projected those three groups in two dimensions.

A comparison of the proportion within the group (PwG), and within the study population (PwP), was carried out for each variable for the purpose of characterizing all three groups. (Figure 3)

CLUSTER 1: This was the largest cluster. A large majority of the patients did not suffer from psychosomatic disease (PwG: $95.1 \%$ vs PwP: $63.4 \%$ ), had no daily use of psychotropic medication (PwG: $85.2 \%$ vs PwP: $56.5 \%$ ) and no reaction due to stress (PwG: $86.9 \%$ vs PwP: $63.4 \%$ ). They used coping strategies (PwG: 88.5 \% vs PwP: 66.4\%) and had a low risk of falls (PwG: $77.0 \%$ vs PwP: $49.6 \%$ ). Very few suffered from osteo-articular disease (PwG: $65.6 \%$ vs Pwp: $44.3 \%$ ).

CLUSTER 2: For the most part, they had osteo-articular disease (PwG: 85.4 \% vs PwP: $55.7 \%$ ), psychosomatic disease (PwG: 65.8 \% vs PwP: 36.6\%), reaction due to severe stress (PwG: 75.6\% vs PwP: $36.6 \%$ ), postural instability (PwG: $75.6 \%$ vs PwP:55.7\%) and had a medium risk of falls (PwG: $63.4 \%$ vs PwP: 38.9\%). Women were a large part of the group (PwG: 78.0\% vs PwP: $53.4 \%$ ). Most of them had a healthy diet (PwG: $75.7 \%$ vs PwP: 51.9\%). 
CLUSTER 3: this group included Patients who, in most cases, lacked proper hygiene (PwG: $79.3 \%$ vs PwG: $23.7 \%$ ) or physical activity (PwG: $96.5 \%$ vs PwG: 63.4\%). None of them had a healthy diet (PwG: 100\% vs PwG: $48.1 \%$ ). Most suffered from psychosomatic disease (PwG: $62.0 \%$ vs PwG:36.6 \%) and used psychotropic drugs on a daily basis (PwG: 79.3\% vs PwG: $43.5 \%$ ). Some of them were socially vulnerable (PwG: $41.4 \%$ vs PwG: $14.5 \%$ ) and had addictions (PwG: $34.5 \%$ vs PwG: $13.7 \%$ ) as a psychological factor. They frequently failed to comply with screening (PwG: $55.2 \%$ vs PwG: $29.8 \%$ ) and did not adopt coping strategies (PwG: 62.0\% vs PwG: 33.6\%).

\section{Status at 24 months}

44 patients (36.6 \% of the cohort) belong to the D group and $76(63.4 \%)$ to the NTR group. Variables of each group are reported in TABLE 2.

The analysis highlighted several characteristics for the patients belonging to the $D$ group:

- they were more likely to suffer from postural instability $(73 \%$ vs $49 \%$, p-value $=0.018)$

- They were more likely to be single or widowed ( $52 \%$ vs $30 \%$, $p$-value $=0.028)$

- Equipment at home was more readily available (39\% vs $13 \%$, p-value $=0.003)$

- More human help was available at home $(52 \%$ vs $26 \%$, p-value $=0,008)$

- Their medical history was detailed and more complex (93\% vs $68 \%$, $\mathrm{p}$-value $=0.004$ ).

Among the quantitative variables, six were significant with an alpha-risk at $5 \%$ :

- the patients in the D-group were older (80 years old vs 69 yo, p-value $<0.001$ )

- They had more diseases, taking into account both chronic and acute conditions ( 7 vs $6, p$-value $=$ 0,016)

- They visited their FPs more often (12 vs 4 , p-value $=0.010)$

- They took more medication per day ( 8 vs $7, p$-value $=0.003)$

\section{Survival analysis}

The overall survival for each variable and between the D and NTR groups was compared using the nonparametric estimation of Kaplan-Meier.

The probability of no decompensation at 24 months was $63.3 \%$ (95\% IC, $(55.3 \%-72.6 \%)$. Two variables had a significant protective effect: excess weight (Log-rank test, $\mathrm{p}$-value $=0.038$ ) and not being single or widowed (Log-rank test, $p$-value $=0.015)$. On the other hand, four were significantly linked to decompensation: detailed and complex medical history (Log-rank test, $\mathrm{p}$-value $=0.003$ ), human help at 
home (Log-rank test, p-value: 0.002), equipment to help at home (Log-rank test, p-value <. 0.001) and multiple complaints patient (Log-rank test, p-value $=0.03)$. (Figure 4$)$

Twenty-five variables appeared to be linked to the risk of decompensation according to a uni-variate analysis by Cox regression. They are referred in TABLE 3 . Sixteen of them were statistically significant with an alpha risk at $5 \%$ (in bold in TABLE 3). Four of them had a protective effect (in italics in TABLE 3) whereas twelve were predictive of decompensation.

Among those sixteen variables, an expert consensus chose four of them (number of FP consultation per year, total number of diseases, CETAF score, multiple complaints) and integrated them into the multivariate analysis.

Due to the adjusted HR, it appeared that a high number of FP consultation per year was significantly associated with decompensation (HR 1.06, IC 95\% [ 1.03; 1,10], p-value <0.001). Patients in the D group had a mean of 12.52 consultations per year compared with 9.08 in the NTR group. Also, a higher total number of diseases seemed to be significantly associated with decompensation (HR 1.12, IC95\% [ 1,01; $1,25]$, p-value $=0.039)$, as patients in the $D$ group had an average of 7.32 diseases compared with 6.11 in the NTR group. (Table 4)

\section{Discussion}

\section{Main results}

The purpose of this survey was to assess which FP criteria in the EGPRN definition of multi morbidity were the most accurate for identifying patients at risk of decompensation. Over 24 months of follow-up, this study highlighted 2 variables associated with decompensation: «number of visits to FPs » and " total number of diseases ». Those two variables are sub themes of « health care consumption » in the definition of multimorbidity, according to the EGPRN.

\section{Strengths and limitations of the study}

Selections bias. FPs who selected multimorbid patients were aware of the study's aim. They may have selected patients with a high risk of decompensation although this bias was minimized by the exclusion criteria " estimated survival less than 3 months ». For the most part, FP recruiters were clinical teachers. It is a well-known fact that clinical teaching FPs undertake work which differs from that of non-teaching FPs (28) (29). Therefore, results with a more general population might be different.

Information bias. To avoid missing data, the questionnaire was modified after the first inclusion period: moving to the next question was impossible without answering the previous one. As this move has effectively avoided omitting data and increased the response rate to some questions, it may have significant impact on the results of the statistical analysis. 
Some data were missing and others were inconsistent. The origin of that issue may be due to some unclear and/or laborious questions and to the length of the questionnaire. Missing data were removed in the statistical analysis to reduce information bias.

Exhaustion after 24 months of follow-up and lack of time to find the answer to some questions may have caused some errors or omitted data.

The 102 chronic diseases reported by the FPs during the study were clustered in a single category, and others were moved into the acute disease or risk factor category. To limit information bias, the clustering was decided by the scientific committee using the ICD 10.

Although the CETAF score was not validated for the under 65-year-olds, the team assumed that it would not be high for people under 65 years old and would have no impact on the statistical analysis result. Therefore, the CETAF score was calculated for every patient (30).

Data transcription from the Evalongo software which was used to complete each questionnaire as an Excel file, in order to ease the analysis, may result in some transcription errors.

\section{Confounding bias}

With regard to the questionnaire, themes and sub themes of the English EGPRN definition of multi morbidity had to be translated into French, and some errors of translation could have occured. Between the two inclusion periods, some quantitative concepts were transformed into qualitative variables, which may have led to errors of transformation.

Given the small number of patients, there was a large number of variables that might have hampered the analysis. With the intention of reducing those difficulties, the decision was made to reduce the number of variables, following expert advice. The variables removed were those which were redundant or not statistically relevant according to the peer group.

Lastly, and despite the fact that it has the virtue of being objective, clinical and valid in literature, the judgment criterion for « decompensation » defined as hospitalization for at least seven days, or death, could be a subject for discussion. However, this choice avoided confounding bias.

\section{Key points}

At the 24-month follow-up, the number of visits to the FPs and total number of diseases were the most useful variables of the EGPRN definition of multimorbidity to predict decompensation. Contrary to the follow-up at 6 months, family problems were not found to be significant.

Every study before that cohort has failed to assess the meaning or the intensity of the relationship between multimorbidity and health outcomes (31) (32). These two variables will help to clarify the 
concept of multimorbidity when the subject in question is specifically the decompensation outcome. In addition, it will ease the burden for FPs in their clinical practice as they work to identify patients who are at risk of decompensation, and to prevent this outcome.

The number of FP consultation per year was also found to be a risk factor for decompensation in the previous studies at $6,9,12,15$ and 18 months (24).

Earlier studies had found an association between multimorbidity and the number of FP visits (18) (33) (34).

The follow up at 6 months found that " age ", « number of visits to FPs » and " family problems » were linked to the risk of decompensation. As « age » is a non-modifiable factor, only " family problems » and « number of visits to FPs » could help to prevent decompensation. At 24 months, « age » was significantly linked to decompensation in the univariate analysis but the expert group didn't integrate it into the multivariate analysis.

As regards " family problems », belonging to the psychosocial risk factor theme, the univariate analysis at 24 months did not find a link with a risk of decompensation, contrary to the previous studies.

These differences may be explained by the fact that more patients were included than previously which can lead to some changes in the characteristics of the population, as could the fact that eleven were lost to follow-up. Finally, the amendments made to the questionnaire may have interfered with the results of the statistical analysis.

\section{Implications for practice, teaching and future research}

In everyday practice, FPs should keep in mind that a multimorbid patient who frequently visits them is at risk of decompensation. This point is easy to deal with and costs nothing to monitor in primary care.

Trainees in family medicine should be aware of this risk factor.

This study is included in an EGPRN project and is destined to be reproduced as a large-scale European study. It is apparent that a clear understanding of the concept of multimorbidity and of the risk factors for decompensation should have a major impact on managing multimorbid patients and on health system expenditure.

It could be interesting that some variables originated from patients, even though this contribution may be considered subjective.

A new, simpler and less demanding questionnaire, should be proposed in further studies in order to avoid errors or data omission due to recruiters being short of time. 
As the total number of diseases was not found to be a risk factor at the previous follow-up, a future study should be run in order to establish a standardized disease classification that could help to identify multimorbidity and its risks of decompensation.

\section{Conclusions}

Once again, the number of FP consultation is found to be a risk factor for decompensation among multimorbid patients in this 24 months of follow-up study. For the first time in this cohort, the total number of diseases was shown to be a risk factor for decompensation. Meanwhile family problems are no longer considered a risk factor. A large-scale study should complete and confirm these outcomes which would, in turn, facilitate research and clinical practice on the concept of Multimorbidity, an key topic of the EGPRN.

\section{Abbreviations}

EGPRN: European General Practitioners Research Network

WHO: World Health Organization

WONCA: World Organization of National Colleges, Academies and Academic Associations of General Practitioners/Family Physicians

FP: family physician FM: family medicine

HR: hazard ratio

MCA: multiple correspondence analysis

HCPC: hierarchical clustering on principal components

NTR: nothing to report

D: decompensation

\section{Declarations}

\section{Acknowledgements}

The authors are grateful for the contributions from the FPs of the RICPRPG (réseau d'investigation Clinique en prévention des risques en population générale) Network specialized in clinical investigations in primary care who parricipated in this survey. We also thank Ms A Gillman for her fine translations in native English. 


\section{Ethics approval and consent to participate:}

The study was approved by the ethics committee of the « Université de Bretagne Occidentale » Faculty of Medicine, Brest. The participants had to sign a written informed consent to participate in the study.

\section{Availability of data and materials}

The datasets used and/or analysed during the current study are available from the corresponding author on reasonable request.

\section{Funding}

None

\section{Consent for publication}

Not applicable

\section{Competing interests:}

The authors declare that they have no competing interests.

\section{Author contributions}

Conceptualization: AP, NP, LS, LGD, DJ, VJ, FJ, GF, LRJY

Data curation: LRJY

Formal analysis: AP, NP, LS, LGD, DJ, VJ, FJ, GF, LRJY

Investigation: AP, NP, LS, LGD, DJ, VJ, FJ, GF, LRJY

Methodology: AP, NP, LS, LGD, DJ, VJ, FJ, GF, LRJY

Project administration: LRJY

Resources: LRJY

Supervision: LRJY

Validation: LRJY 
Writing-original Draft: AP

Writing-review \& editing: AP, NP, LS, LGD, DJ, VJ, FJ, GF, LRJY

All Authors read and approved the final version of the manuscript.

\section{References}

1. Mathers CD, Loncar D. Projections of Global Mortality and Burden of Disease from 2002 to 2030 [Internet]. Vol. 3, PLoS Medicine | www. 2006 [cited 2019 Feb 14]. Available from:

www.plosmedicine.org

2. Mathers CD, Loncar D. Updated projections of global mortality and burden of disease, 2002-2030: data sources, methods and results. Evidence and Information for Policy Working Paper [Internet]. 2005 [cited 2019 Feb 14]. Available from:

https://www.who.int/healthinfo/statistics/bod_projections2030_paper.pdf

3. Soual H. Les dépenses de santé depuis 1950 - Ministère des Solidarités et de la Santé; (1017) [Internet]. [cited 2019 Feb 14]. Available from: https://drees.solidarites-sante.gouv.fr/etudes-etstatistiques/publications/etudes-et-resultats/article/les-depenses-de-sante-depuis-1950

4. Brandlmeier P. [Multimorbidity among elderly patients in an urban general practice]. ZFA (Stuttgart) [Internet]. 1976 Sep 10 [cited 2019 Feb 15];52(25):1269-75. Available from: http://www.ncbi.nlm.nih.gov/pubmed/983240

5. Now More Than Ever UNIVERSAL COVERAGE REFORMS SERVICE DELIVERY REFORMS LEADERSHIP REFORMS PUBLIC POLICY REFORMS [Internet]. [cited 2019 Feb 14]. Available from: https://www.who.int/whr/2008/whr08_en.pdf

6. Almirall J, Fortin M. The coexistence of terms to describe the presence of multiple concurrent diseases [Internet]. Vol. 3, Journal of Comorbidity. 2013 [cited 2019 Feb 14]. Available from: www.swissmedicalpress.com

7. van den Akker M, Buntinx F, Knottnerus JA. Comorbidity or multimorbidity. Eur J Gen Pract [Internet]. 1996 Jan 11 [cited 2019 Feb 15];2(2):65-70. Available from: http://www.tandfonline.com/doi/full/10.3109/13814789609162146

8. van den Bussche H, Schäfer I, Wiese B, Dahlhaus A, Fuchs A, Gensichen J, et al. A comparative study demonstrated that prevalence figures on multimorbidity require cautious interpretation when drawn from a single database. J Clin Epidemiol [Internet]. 2013 Feb 1 [cited 2019 Feb 15];66(2):209-17. Available from: http://www.ncbi.nlm.nih.gov/pubmed/23257152

9. Muth C, Beyer M, Fortin M, Rochon J, Oswald F, Valderas JM, et al. Multimorbidity's research challenges and priorities from a clinical perspective: The case of 'Mr Curran.' Eur J Gen Pract [Internet]. 2014 Jun 25 [cited 2019 Feb 15];20(2):139-47. Available from: http://www.tandfonline.com/doi/full/10.3109/13814788.2013.839651 
10. Muth C, Van Den Akker M, Blom JW, Mallen CD, Rochon J, Schellevis FG, et al. The Ariadne principles: how to handle multimorbidity in primary care consultations [Internet]. Vol. 12, BMC Medicine. 2014 [cited 2019 Feb 15]. Available from: http://www.biomedcentral.com/17417015/12/222.http://www.biomedcentral.com/1741-7015/12/223

11. Huber M, Knottnerus JA, Green L, van der Horst H, Jadad AR, Kromhout D, et al. How should we define health? BMJ [Internet]. 2011 Jul 26 [cited 2019 Feb 15];343:d4163. Available from: http://www.ncbi.nlm.nih.gov/pubmed/21791490

12. Willadsen TG, Bebe A, Køster-Rasmussen R, Jarbøl DE, Guassora AD, Waldorff FB, et al. The role of diseases, risk factors and symptoms in the definition of multimorbidity-a systematic review. Scand J Prim Health Care [Internet]. 2016 Apr 2 [cited 2019 Feb 15];34(2):112-21. Available from: http://www.tandfonline.com/doi/full/10.3109/02813432.2016.1153242

13. Allen J, Gay B, Paris F, Crebolder H, Catholic JH, Svab I. The Role of the General Practitioner and A description of the Core Competencies of the General Practitioner / Family Physician. Prepared for WONCA EUROPE (The European Society of General Practice/ Family Medicine), 2002 [Internet]. [cited 2019 Feb 15]. Available from: http://www.woncaeurope.org/sites/default/files/documents/Definition 3rd ed 2011 with revised wonca tree.pdf

14. Hummers-Pradier E, Beyer M, Chevallier P, Eilat-Tsanani S, Lionis C, Peremans L, et al. Series: The research agenda for general practice/family medicine and primary health care in Europe. Part 4. Results: Specific problem solving skills. Eur J Gen Pract [Internet]. 2010 Sep 8 [cited 2019 Feb 14];16(3):174-81. Available from: http://www.tandfonline.com/doi/full/10.3109/13814788.2010.504982

15. Le Reste JY, Nabbe P, Lygidakis C, Doerr C, Lingner H, Czachowski S, et al. A research group from the European General Practice Research Network (EGPRN) explores the concept of multimorbidity for further research into long term care. J Am Med Dir Assoc [Internet]. 2013 Feb 1 [cited 2019 Feb 14];14(2):132-3. Available from: http://www.ncbi.nlm.nih.gov/pubmed/22959729

16. Le Reste JY, Nabbe P, Manceau B, Lygidakis C, Doerr C, Lingner H, et al. The European General Practice Research Network presents a comprehensive definition of multimorbidity in family medicine and long term care, following a systematic review of relevant literature. J Am Med Dir Assoc [Internet]. 2013 May 1 [cited 2019 Feb 14];14(5):319-25. Available from: http://www.ncbi.nlm.nih.gov/pubmed/23411065

17. Le Reste JY, Nabbe P, Lazic D, Assenova R, Lingner H, Czachowski S, et al. How do general practitioners recognize the definition of multimorbidity? A European qualitative study. Eur J Gen Pract [Internet]. 2016 Jul 2 [cited 2019 Feb 15];22(3):159-68. Available from: https://www.tandfonline.com/doi/full/10.3109/13814788.2015.1136619

18. Le Reste JY, Nabbe P, Rivet C, Lygidakis C, Doerr C, Czachowski S, et al. The European general practice research network presents the translations of its comprehensive definition of multimorbidity in family medicine in ten European languages. PLoS One. 2015;10(1):1-13. 
19. Galvin R, Gilleit Y, Wallace E, Cousins G, Bolmer M, Rainer T, et al. Adverse outcomes in older adults attending emergency departments: a systematic review and meta-analysis of the Identification of Seniors At Risk (ISAR) screening tool. Age Ageing [Internet]. 2016 Dec 17 [cited 2019 Feb 15];46(2):179-86. Available from: https://academic.oup.com/ageing/articlelookup/doi/10.1093/ageing/afw233

20. Le Reste J, Nabbe P, Lingner H, Kasuba Lazic D, Assenova R, Munoz M, et al. What research agenda could be generated from the European General Practice Research Network concept of Multimorbidity in Family Practice? BMC Fam Pract [Internet]. 2015 Dec 17 [cited 2019 Feb 15];16(1):125. Available from: http://bmcfampract.biomedcentral.com/articles/10.1186/s12875-015-0337-3

21. Garrido-Elustondo S, Reneses B, Navalón A, Martín O, Ramos I, Fuentes M. Atención Primaria Capacidad de detección de patología psiquiátrica por el médico de familia. Atención Primaria [Internet]. 2016 [cited 2019 Feb 15];48(7):449-57. Available from:

www.elsevier.es/aphttp://dx.doi.org/10.1016/j.aprim.2015.09.0090212-6567/

22. Lee L, Fcfp C, Heckman G, Mckelvie R, Jong P, D' T, et al. Physicians' perceptions of capacity building for managing chronic disease in seniors using integrated interprofessional care models [Internet]. Vol. 61. [cited 2019 Feb 15]. Available from: https://www.ncbi.nlm.nih.gov/pmc/articles/PMC4369631/pdf/061e148.pdf

23. Lussier M-T, Richard C, Glaser E, Roberge $\mathrm{D}$. The impact of a primary care e-communication intervention on the participation of chronic disease patients who had not reached guideline suggested treatment goals. Patient Educ Couns [Internet]. 2016 Apr [cited 2019 Feb 15];99(4):53041. Available from: http://www.ncbi.nlm.nih.gov/pubmed/26657041

24. Le Reste JY, Nabbe P, Billot Grasset A, Le Floch B, Grall P, Derriennic J, et al. Multimorbid outpatients: A high frequency of FP appointments and/or family difficulties, should alert FPs to the possibility of death or acute hospitalization occurring within six months; A primary care feasibility study. Marengoni A, editor. PLoS One [Internet]. 2017 Nov 2 [cited 2019 Feb 15];12(11):e0186931. Available from: https://dx.plos.org/10.1371/journal.pone.0186931

25. Bongue B, Hugues J, Achour É, Colvez A, Sass C. Mieux prévenir les chutes chez les personnes âgées. Soins Gérontologie [Internet]. 2016 Jul [cited 2019 Feb 16];21(120):24-9. Available from: https://linkinghub.elsevier.com/retrieve/pii/S1268603416300329

26. DRESS. Comparaison internationale des dépenses hospitalières. Paris; 2006. [Internet]. [cited 2019 Feb 16]. Available from: https://drees.solidarites-sante.gouv.fr/IMG/pdf/cns_2017.pdf

27. Wauters T. Définition de la fragilité à partir des critères retenus dans la littérature [Internet]. [cited 2019 Feb 16]. Available from: https://dumas.ccsd.cnrs.fr/dumas-01599814

28. Peto V, Coulter A, Bond A. Factors affecting general practitioners' recruitment of patients into a prospective study. Fam Pract [Internet]. 1993 Jun [cited 2019 Feb 16];10(2):207-11. Available from: http://www.ncbi.nlm.nih.gov/pubmed/8359613

29. Letrilliart L, Rigault-Fossier P, Fossier B, Kellou N, Paumier F, Bois C, et al. Comparison of French training and non-training general practices: a cross-sectional study. 2016 [cited 2019 Feb 16]; 
Available from: https://bmcmededuc.biomedcentral.com/track/pdf/10.1186/s12909-016-0649-6

30. HAS. Réponse à la saisine du 3 juillet 2012 en application de l'article L.161-39 du code de la sécurité sociale. Référentiel concernant l'évaluation du risque de chutes chez le sujet âgé autonome et sa prévention. 2012 p. 1-28.

31. Winograd $\mathrm{CH}$. Targeting strategies: an overview of criteria and outcomes. J Am Geriatr Soc [Internet]. 1991 Sep [cited 2019 Feb 16];39(9 Pt 2):25S-35S. Available from:

http://www.ncbi.nlm.nih.gov/pubmed/1885875

32. Speechley M, Tinetti M. Falls and Injuries in Frail and Vigorous Community Elderly Persons. J Am Geriatr Soc [Internet]. 1991 Jan 1 [cited 2019 Feb 16];39(1):46-52. Available from: http://doi.wiley.com/10.1111/j.1532-5415.1991.tb05905.x

33. Palladino R, Tayu Lee J, Ashworth M, Triassi M, Millett C. Associations between multimorbidity, healthcare utilisation and health status: evidence from 16 European countries. Age Ageing [Internet]. 2016 May [cited 2019 Feb 16];45(3):431-5. Available from:

http://www.ncbi.nlm.nih.gov/pubmed/27013499

34. Salisbury C, Johnson L, Purdy S, Valderas JM, Montgomery AA. Epidemiology and impact of multimorbidity in primary care: a retrospective cohort study. Br J Gen Pract [Internet]. 2011 Jan 1 [cited 2019 Feb 16];61(582):e12-21. Available from: http://www.ncbi.nlm.nih.gov/pubmed/21401985

\section{Tables}

Table 1: Themes and subthemes of the multimorbidity 


\begin{tabular}{|c|c|}
\hline THEMES & SUBTHEMES \\
\hline Chronic disease & $\begin{array}{l}\text { Chronic condition } \\
\text { Chronic diseases } \\
\text { Complexity characteristics of chronic disease } \\
\text { Psychosomatic disease }\end{array}$ \\
\hline Acute disease & $\begin{array}{l}\text { Acute condition } \\
\text { Acute disease } \\
\text { Complexity characteristics of acute disease } \\
\text { Reaction to severe stress and acute disorders }\end{array}$ \\
\hline $\begin{array}{l}\text { Biopsychosocial factors and somatic risk } \\
\text { factors }\end{array}$ & \begin{tabular}{||l} 
Demographic risk factor \\
Pifestyle \\
Physionts beliefs / expectations \\
Psychological risk factors \\
Psychosocial risk factors \\
Sociodemographic characteristics \\
Somatic risk factors
\end{tabular} \\
\hline Coping & Patient's coping strategies \\
\hline Burden of diseases & \begin{tabular}{|l} 
Disease morbidity \\
Disease complication
\end{tabular} \\
\hline Health care consumption & $\begin{array}{l}\text { Use of carers } \\
\text { Disease management } \\
\text { Health system } \\
\text { Health care policy } \\
\text { Health care } \\
\text { Health care services } \\
\text { Malpractice } \\
\text { Page 18/29 }\end{array}$ \\
\hline
\end{tabular}




\begin{tabular}{|c|c|}
\hline & \begin{tabular}{|l} 
Assessment \\
Medical history \\
Pain \\
Polypharmacy procedure \\
Prevention \\
Symptoms/signs/complaints \\
Treatment or medication \\
Cost of care
\end{tabular} \\
\hline Disability & $\begin{array}{l}\text { Handicap } \\
\text { Functional impairments }\end{array}$ \\
\hline Quality of life & $\begin{array}{l}\text { Health status } \\
\text { Impairment } \\
\text { Morbidity implication } \\
\text { Quality of life }\end{array}$ \\
\hline Frailty & Frailty \\
\hline Social network & $\begin{array}{l}\text { Dependence on social network } \\
\text { Family's coping strategies } \\
\text { Social isolation } \\
\text { Social network } \\
\text { Support from social network }\end{array}$ \\
\hline Health outcomes & $\begin{array}{l}\text { Outcomes } \\
\text { Medical research epidemiology } \\
\text { Mortality }\end{array}$ \\
\hline Core competencies of FP & $\begin{array}{l}\text { Holistic approach } \\
\text { Practical experience of general practitioners with } \\
\text { patients }\end{array}$ \\
\hline
\end{tabular}




\begin{tabular}{|l||l|l|} 
& General practitioner, as a sole expert in \\
multimorbidity & Expertise of the general practitioner \\
& "Gut feeling"/Intuition \\
& Person-centred care \\
\hline \hline Relationship between FP and patient & Primary care management \\
\hline & Specific problem-solving skills \\
\hline
\end{tabular}

Table 2 : characteristics of D group and NTR group for each variable as described by FPs 


\begin{tabular}{|c|c|c|c|c|c|c|c|c|}
\hline \multirow{3}{*}{\multicolumn{2}{|c|}{ Qualitative variables }} & \multirow{2}{*}{\multicolumn{2}{|c|}{$\begin{array}{c}\text { Study } \\
\text { Population } \\
\mathrm{N}=120(100 \%)\end{array}$}} & & & & & \\
\hline & & & & \multicolumn{2}{|c|}{\begin{tabular}{l}
\multicolumn{2}{c}{ Decompensation } \\
(D) \\
$44(36,6 \%)$
\end{tabular}} & \multicolumn{2}{|c|}{ 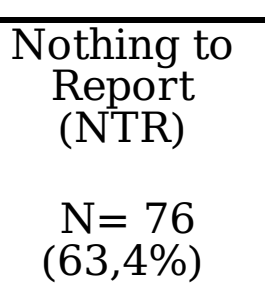 } & \multirow{2}{*}{\begin{tabular}{|c|} 
p-value \\
\\
Chi $^{2} /$ Fisher
\end{tabular}} \\
\hline & & $\mathrm{N}$ & $\%$ & $\mathrm{~N}$ & $\%$ & $\mathrm{~N}$ & $\%$ & \\
\hline \multicolumn{2}{|c|}{ Men } & 57 & $48 \%$ & 22 & $50 \%$ & 35 & $46 \%$ & \multirow[t]{2}{*}{0,820} \\
\hline \multicolumn{2}{|c|}{ Women } & 63 & $52 \%$ & 22 & $50 \%$ & 41 & $54 \%$ & \\
\hline \multicolumn{9}{|c|}{ Somatic risk factors and disease } \\
\hline \multicolumn{2}{|c|}{ Osteoarticular disease } & 66 & $55 \%$ & 29 & $66 \%$ & 37 & $49 \%$ & 0,102 \\
\hline \multicolumn{2}{|c|}{ Hypertension } & 76 & $63 \%$ & 32 & $73 \%$ & 44 & $58 \%$ & 0,153 \\
\hline \multicolumn{2}{|c|}{ Hypercholesterolemia } & 52 & $43 \%$ & 20 & $45 \%$ & 32 & $42 \%$ & 0,868 \\
\hline \multicolumn{2}{|c|}{ Diabetes } & 31 & $26 \%$ & 10 & $23 \%$ & 21 & $28 \%$ & 0,708 \\
\hline \multicolumn{2}{|c|}{ Psychosomatic disease } & 43 & $36 \%$ & 14 & $32 \%$ & 29 & $38 \%$ & 0,617 \\
\hline \multicolumn{2}{|c|}{$\begin{array}{l}\text { Complexity of chronic } \\
\text { disease }\end{array}$} & 61 & $51 \%$ & 27 & $61 \%$ & 34 & $45 \%$ & 0,117 \\
\hline \multicolumn{2}{|c|}{$\begin{array}{l}\text { Complication of acute } \\
\text { disease }\end{array}$} & 12 & $10 \%$ & 4 & $9 \%$ & 8 & $11 \%$ & 1,000 \\
\hline \multicolumn{2}{|c|}{$\begin{array}{c}\text { Reaction to severe } \\
\text { stress }\end{array}$} & 44 & $37 \%$ & 19 & $43 \%$ & 24 & $33 \%$ & 0,352 \\
\hline \multicolumn{2}{|c|}{$\begin{array}{c}\text { Cardiovascular family } \\
\text { history }\end{array}$} & 27 & $23 \%$ & 6 & $14 \%$ & 21 & $28 \%$ & 0,123 \\
\hline \multicolumn{2}{|c|}{ Overweight } & 47 & $39 \%$ & 12 & $27 \%$ & 35 & $46 \%$ & 0,066 \\
\hline \multicolumn{2}{|c|}{ Immunosuppression } & 15 & $13 \%$ & 6 & $14 \%$ & 9 & $12 \%$ & 1,000 \\
\hline \multicolumn{2}{|c|}{ Postural instability } & 69 & $58 \%$ & 32 & $73 \%$ & 37 & $49 \%$ & 0,018 \\
\hline \multicolumn{2}{|c|}{ Falls in year } & 25 & $21 \%$ & 12 & $27 \%$ & 13 & $17 \%$ & 0,276 \\
\hline \multirow{4}{*}{$\begin{array}{l}\text { Number } \\
\text { of falls in } \\
\text { year }\end{array}$} & & 95 & $79 \%$ & 32 & $73 \%$ & 63 & $83 \%$ & \multirow[t]{4}{*}{0,253} \\
\hline & 1 & 16 & $13 \%$ & 6 & $14 \%$ & 10 & $13 \%$ & \\
\hline & 2 & 6 & $5 \%$ & 4 & $9 \%$ & 2 & $3 \%$ & \\
\hline & 3 or more & 3 & $3 \%$ & 2 & $5 \%$ & 1 & $1 \%$ & \\
\hline
\end{tabular}




\begin{tabular}{|c|c|c|c|c|c|c|c|c|}
\hline \multirow{3}{*}{$\begin{array}{l}\text { CETAF } \\
\text { Score }\end{array}$} & Great risk & 12 & $10 \%$ & 6 & $14 \%$ & 6 & $8 \%$ & \multirow[t]{3}{*}{0,315} \\
\hline & Medium risk & 62 & $52 \%$ & 19 & $43 \%$ & 43 & $57 \%$ & \\
\hline & Small risk & 46 & $38 \%$ & 19 & $43 \%$ & 27 & $36 \%$ & \\
\hline
\end{tabular}

Psychological risk factor

\begin{tabular}{|c|c|c|c|c|c|c|c|}
\hline Risk behaviour & 3 & $2,5 \%$ & 0 & $0 \%$ & 3 & $4 \%$ & 0,297 \\
\hline Suicide risk & 5 & $4 \%$ & 3 & $7 \%$ & 2 & $3 \%$ & 0,355 \\
\hline Addiction & 14 & $12 \%$ & 2 & $5 \%$ & 12 & $16 \%$ & 0,120 \\
\hline $\begin{array}{c}\text { No psychological risk } \\
\text { factor }\end{array}$ & 102 & $85 \%$ & 41 & $93 \%$ & 61 & $80 \%$ & 0,100 \\
\hline
\end{tabular}

Psychosocial risk factor

\begin{tabular}{|c|c|c|c|c|c|c|c|}
\hline Unemployment & 3 & $2,5 \%$ & 0 & $0 \%$ & 3 & $4 \%$ & 0,297 \\
\hline Marital problems & 9 & $8 \%$ & 4 & $9 \%$ & 5 & $7 \%$ & 0,886 \\
\hline Stress at work & 9 & $8 \%$ & 3 & $7 \%$ & 6 & $8 \%$ & 1,000 \\
\hline Family problems & 20 & $17 \%$ & 10 & $23 \%$ & 10 & $13 \%$ & 0,271 \\
\hline $\begin{array}{l}\text { Financial and social } \\
\text { vulnerability }\end{array}$ & 13 & $11 \%$ & 2 & $5 \%$ & 11 & $14 \%$ & 0,167 \\
\hline $\begin{array}{c}\text { Death of one or more } \\
\text { loved ones }\end{array}$ & 21 & $18 \%$ & 10 & $23 \%$ & 11 & $14 \%$ & 0,370 \\
\hline Divorce & 2 & $2 \%$ & 0 & $0 \%$ & 2 & $3 \%$ & 0,532 \\
\hline \multicolumn{8}{|l|}{ Lifestyle } \\
\hline Good hygiene & 92 & $77 \%$ & 34 & $77 \%$ & 58 & $76 \%$ & 1,000 \\
\hline Physical activity & 45 & $38 \%$ & 16 & $36 \%$ & 29 & $38 \%$ & 1,000 \\
\hline Healthy diet & 63 & $50 \%$ & 26 & $59 \%$ & 37 & $49 \%$ & 0,363 \\
\hline No positive answer & 21 & $18 \%$ & 6 & $14 \%$ & 15 & $20 \%$ & 0,550 \\
\hline \multicolumn{8}{|c|}{ Socio professional category (SPC) } \\
\hline \begin{tabular}{l|l} 
& Farmer
\end{tabular} & 15 & $13 \%$ & 5 & $12 \%$ & 10 & $13 \%$ & \multirow[t]{3}{*}{0,743} \\
\hline Artisan & 17 & $14 \%$ & 8 & $19 \%$ & 9 & $12 \%$ & \\
\hline Executive & 7 & $6 \%$ & 1 & $2 \%$ & 6 & $8 \%$ & \\
\hline
\end{tabular}




\begin{tabular}{|c|c|c|c|c|c|c|c|}
\hline \begin{tabular}{c|c} 
Intermediate \\
profession
\end{tabular} & 19 & $16 \%$ & 8 & $19 \%$ & 11 & $14 \%$ & \\
\hline Employee & 18 & $15 \%$ & 7 & $16 \%$ & 11 & $14 \%$ & \\
\hline Worker & 18 & $15 \%$ & 7 & $16 \%$ & 11 & $14 \%$ & \\
\hline Unemployed & 25 & $21 \%$ & 7 & $16 \%$ & 18 & $24 \%$ & \\
\hline \multicolumn{8}{|l|}{ Family situation } \\
\hline In a relationship & 74 & $62 \%$ & 21 & $48 \%$ & 53 & $70 \%$ & 0,028 \\
\hline Single or widowed & 46 & $38 \%$ & 23 & $52 \%$ & 23 & $30 \%$ & 0,028 \\
\hline Having children & 31 & $26 \%$ & 11 & $25 \%$ & 20 & $26 \%$ & 1,000 \\
\hline \multicolumn{8}{|l|}{ Entourage characteristics } \\
\hline Absence of entourage & 17 & $14 \%$ & 8 & $18 \%$ & 9 & $12 \%$ & 0,491 \\
\hline Supporting entourage & 66 & $55 \%$ & 23 & $52 \%$ & 43 & $57 \%$ & 0,790 \\
\hline $\begin{array}{l}\text { Dependency of } \\
\text { entourage }\end{array}$ & 22 & $18 \%$ & 12 & $27 \%$ & 10 & $13 \%$ & 0,093 \\
\hline Coping strategies & 24 & $20 \%$ & 13 & $30 \%$ & 11 & $14 \%$ & 0,080 \\
\hline \multicolumn{8}{|l|}{ Health care } \\
\hline $\begin{array}{c}\text { Pharmacological } \\
\text { treatment }\end{array}$ & 120 & $100 \%$ & 44 & $100 \%$ & 76 & $100 \%$ & NI \\
\hline Treatment at risk & 43 & $36 \%$ & 18 & $41 \%$ & 25 & $33 \%$ & 0,493 \\
\hline $\begin{array}{l}\text { Daily use of } \\
\text { psychotropic } \\
\text { medication }\end{array}$ & 50 & $42 \%$ & 16 & $36 \%$ & 43 & $45 \%$ & 0,481 \\
\hline $\begin{array}{l}\text { Coordination } \\
\text { procedures }\end{array}$ & 63 & $53 \%$ & 24 & $55 \%$ & 39 & $51 \%$ & 0,879 \\
\hline $\begin{array}{l}\text { Good communication } \\
\text { between other carers }\end{array}$ & 107 & $89 \%$ & 37 & $84 \%$ & 70 & $92 \%$ & 0,291 \\
\hline Neglect of the patient & 6 & $5 \%$ & 2 & $5 \%$ & 4 & $5 \%$ & 1,000 \\
\hline $\begin{array}{l}\text { Patient victim of } \\
\text { iatrogeny }\end{array}$ & 14 & $12 \%$ & 3 & $7 \mathrm{ù}$ & 11 & $14 \%$ & 0,335 \\
\hline $\begin{array}{c}\text { Equipment for patient } \\
\text { at home }\end{array}$ & 27 & $23 \%$ & 17 & $39 \%$ & 10 & $13 \%$ & 0,003 \\
\hline
\end{tabular}




\begin{tabular}{|c|c|c|c|c|c|c|c|}
\hline Human help at home & 43 & $36 \%$ & 23 & $52 \%$ & 20 & $26 \%$ & 0,008 \\
\hline $\begin{array}{l}\text { Lack of time and } \\
\text { remuneration }\end{array}$ & 34 & $28 \%$ & 15 & $34 \%$ & 19 & $25 \%$ & 0,393 \\
\hline $\begin{array}{l}\text { Detailed and complex } \\
\text { medical history }\end{array}$ & 93 & $78 \%$ & 41 & $93 \%$ & 52 & $68 \%$ & 0,004 \\
\hline $\begin{array}{l}\text { Vaccination97 } \\
\text { recommended }\end{array}$ & 97 & $81 \%$ & 36 & $82 \%$ & 61 & $80 \%$ & 1,000 \\
\hline Screening proposed & 70 & $58 \%$ & 24 & $55 \%$ & 46 & $61 \%$ & 0,654 \\
\hline Screening accepted & 78 & $70 \%$ & 30 & $73 \%$ & 48 & $68 \%$ & 0,686 \\
\hline $\begin{array}{l}\text { Therapeutic education } \\
\text { proposed }\end{array}$ & 22 & $18 \%$ & 8 & $18 \%$ & 14 & $18 \%$ & 1,000 \\
\hline Patient in pain & 54 & $45 \%$ & 24 & $55 \%$ & 30 & $39 \%$ & 0,159 \\
\hline $\begin{array}{c}\text { Residing in nursing } \\
\text { home }\end{array}$ & 3 & $2,5 \%$ & 2 & $5 \%$ & 1 & $1 \%$ & 0,553 \\
\hline Multiple complaints & 38 & $32 \%$ & 19 & $43 \%$ & 19 & $25 \%$ & 0,063 \\
\hline $\begin{array}{l}\text { Good knowledge of } \\
\text { health care system }\end{array}$ & 106 & $88 \%$ & 40 & $91 \%$ & 66 & $87 \%$ & 0,709 \\
\hline $\begin{array}{c}\text { Used to solving } \\
\text { complex problems }\end{array}$ & 116 & $97 \%$ & 42 & $95 \%$ & 74 & $97 \%$ & 0,623 \\
\hline $\begin{array}{l}\text { Global vision of } \\
\text { patient's diseases }\end{array}$ & 119 & $99 \%$ & 43 & $98 \%$ & 76 & $100 \%$ & 0,367 \\
\hline $\begin{array}{l}\text { Cares focused on needs } \\
\text { and expectations }\end{array}$ & 118 & $98 \%$ & 43 & $98 \%$ & 75 & $99 \%$ & 1,000 \\
\hline Long term relationship & 119 & $99 \%$ & 43 & $98 \%$ & 76 & $100 \%$ & 0,367 \\
\hline $\begin{array}{l}\text { Feeling that something } \\
\text { bad had happened }\end{array}$ & 78 & $65 \%$ & 32 & $73 \%$ & 61 & $46 \%$ & 0,249 \\
\hline $\begin{array}{l}\text { Good quality } \\
\text { communication }\end{array}$ & 119 & $99 \%$ & 43 & $98 \%$ & 76 & $100 \%$ & 0,367 \\
\hline $\begin{array}{l}\text { Impact on the quality } \\
\text { of follow-up }\end{array}$ & 96 & $80 \%$ & 37 & $84 \%$ & 59 & $78 \%$ & 0,538 \\
\hline & \multicolumn{2}{|c|}{ Study } & \multicolumn{2}{|c|}{ Decompensation } & \multicolumn{2}{|c|}{ Nothing to } & $\overline{P \text { value }}$ \\
\hline
\end{tabular}




\begin{tabular}{|c|c|c|c|c|c|c|c|}
\hline & \multicolumn{2}{|c|}{$\begin{array}{l}\text { Population } \\
\qquad \begin{array}{l}\mathrm{N}=120 \\
(100 \%)\end{array}\end{array}$} & \multicolumn{2}{|c|}{$44(36,6 \%)$} & \multicolumn{2}{|c|}{$\begin{array}{l}\begin{array}{c}\text { Report } \\
\text { (NTR) }\end{array} \\
\begin{array}{l}\mathrm{N}=76 \\
(63,4 \%)\end{array}\end{array}$} & \\
\hline Quantitative variables & Median & (Q1-Q3) & Median & (Q1-Q3) & Median & \begin{tabular}{|l} 
Q1- \\
Q3)
\end{tabular} & $\begin{array}{c}\text { Wilcoxon/ } \\
\text { Mann- } \\
\text { Whitney }\end{array}$ \\
\hline Average age & 73,0 & $\overline{(52-30)}$ & 80,5 & $(73-85)$ & 69,0 & $\begin{array}{l}(61- \\
78)\end{array}$ & $<0,001$ \\
\hline $\begin{array}{c}\text { Total number of } \\
\text { diseases }\end{array}$ & 6,0 & $(5-8)$ & 7,0 & $(6-8)$ & 6,0 & $(5-8)$ & 0,016 \\
\hline $\begin{array}{c}\text { Number of chronic } \\
\text { diseases }\end{array}$ & 6,0 & $(4-8)$ & 6,0 & $(5-8)$ & 5,0 & $(4-7)$ & 0,019 \\
\hline $\begin{array}{c}\text { Number of Acute } \\
\text { diseases }\end{array}$ & 0,0 & $(0-1)$ & 0,0 & $(0-1)$ & 0,5 & $(0-1)$ & 0,643 \\
\hline Number of treatments & 7,0 & $(5-9)$ & 8,0 & $(6-10)$ & 7,0 & $(4-8)$ & 0,003 \\
\hline $\begin{array}{c}\text { Number of FP } \\
\text { consultation per year }\end{array}$ & 10,0 & $(6-12)$ & 12,0 & $(7-14)$ & 8,0 & $\begin{array}{l}(6- \\
12)\end{array}$ & 0,021 \\
\hline $\begin{array}{l}\text { Number of specialist } \\
\text { consultation per year }\end{array}$ & 3,0 & $(2-5)$ & 3,0 & $(2-5)$ & 3,0 & $(2-5)$ & 0,755 \\
\hline $\begin{array}{c}\text { Number of times health } \\
\text { paramedics used per } \\
\text { year }\end{array}$ & 6,0 & $(2-30)$ & 12,0 & $(4-43)$ & 4,0 & $\begin{array}{l}(2- \\
20)\end{array}$ & 0,010 \\
\hline $\begin{array}{c}\text { Number of biological } \\
\text { tests performed per } \\
\text { year }\end{array}$ & 1,0 & $(1-2)$ & 2,0 & $(2-3)$ & 1,0 & $(1-2)$ & 0,447 \\
\hline $\begin{array}{c}\text { Number of medical } \\
\text { imaging tests per year }\end{array}$ & 1,0 & $(0-2)$ & 1,0 & $(1-2)$ & 1,5 & $(0-2)$ & 0,734 \\
\hline CETAF score & 3,0 & $(2-5)$ & 4,0 & $(2-5)$ & 3,0 & $(2-4)$ & 0,075 \\
\hline
\end{tabular}

\section{NI : not interpretable Bold : significantly results}

Table 3: Univariate analysis 


\begin{tabular}{|c|c|c|c|}
\hline & HR & IC95\% & $\mathbf{p}$ \\
\hline Joint or bone diseases & 1,80 & {$[0,93 ; 3,54]$} & 0,083 \\
\hline Chronic disease complication & 1,68 & {$[0,91 ; 3,08]$} & 0,095 \\
\hline Family history of cardiovascular disorders & 0,46 & {$[0,19 ; 1,08]$} & 0,075 \\
\hline Excess weight & 0,51 & {$[0,26 ; 0,98]$} & 0,044 \\
\hline Postural instability & 2,28 & {$[1,17 ; 4,43]$} & 0,015 \\
\hline Family problems & 1,84 & {$[0,91 ; 3,73]$} & 0,090 \\
\hline In a relationship & 0,49 & {$[0,27 ; 0,89]$} & 0,019 \\
\hline Coping strategies & 1,85 & {$[0,97 ; 3,54]$} & 0,062 \\
\hline Equipment for patient at home & 2,80 & {$[1,52 ; 5,15]$} & 0,001 \\
\hline Human help at home & 2,48 & {$[1,37 ; 4,49]$} & 0,003 \\
\hline Detailed and complex medical history & 4,97 & {$[1,54 ; 16,06]$} & 0,007 \\
\hline Multiple complaints & 1,93 & {$[1,06 ; 3,51]$} & 0,031 \\
\hline Dependency of entourage & 1,94 & {$[1,00 ; 3,77]$} & 0,051 \\
\hline Global vision of patient's diseases & 0,05 & {$[0,01 ; 0,43]$} & 0,006 \\
\hline Long term relationship & 0,05 & {$[0,01 ; 0,43]$} & 0,006 \\
\hline Good quality of communication & 0,05 & {$[0,01 ; 0,43]$} & 0,006 \\
\hline Number of times health paramedics used per year & 1,00 & {$[1,00 ; 1,00]$} & 0,006 \\
\hline Age & 1,07 & {$[1,03 ; 1,11]$} & $<0,001$ \\
\hline $\begin{array}{l}\text { Number of FP } \\
\text { consultation per year }\end{array}$ & 1,07 & {$[1,03 ; 1,11]$} & $<0,001$ \\
\hline Number of treatments & 1,14 & {$[1,05 ; 1,25]$} & 0,003 \\
\hline Number of chronic diseases & 1,15 & {$[1,03 ; 1,28]$} & 0,012 \\
\hline CETAF score & 1,17 & {$[1,03 ; 1,34]$} & 0,015 \\
\hline No psychological risk factor & 2,70 & {$[0,84 ; 8,74]$} & 0,096 \\
\hline Total number of diseases & 1,15 & {$[1,03 ; 1,28]$} & 0,012 \\
\hline Number of biological tests per year & 1,12 & {$[0,99 ; 1,27]$} & 0,060 \\
\hline
\end{tabular}




\section{In Bold : significant results in Italics : protective effect}

Table 4: Adjusted Hazard Ratio after multivariate analysis:

\begin{tabular}{|l|c|c|c|}
\cline { 2 - 4 } \multicolumn{1}{l|}{} & HR & IC95\% & $\mathbf{p}$ \\
\cline { 2 - 4 } & & & \\
\hline consultation per year & 1,06 & {$[1,03 ; 1,10]$} & $<0,001$ \\
\hline Total number of diseases & 1,12 & {$[1,01 ; 1,25]$} & $\mathbf{0 , 0 3 9}$ \\
\hline
\end{tabular}

\section{Figures}

Figure 1 : Flow Chart

137 completed questionnaires
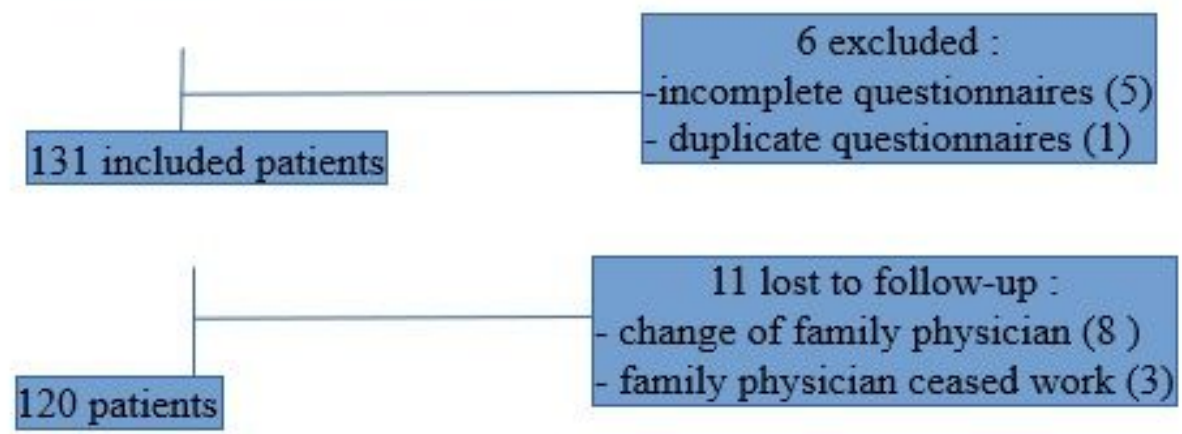

Figure 1

Flow Chart 


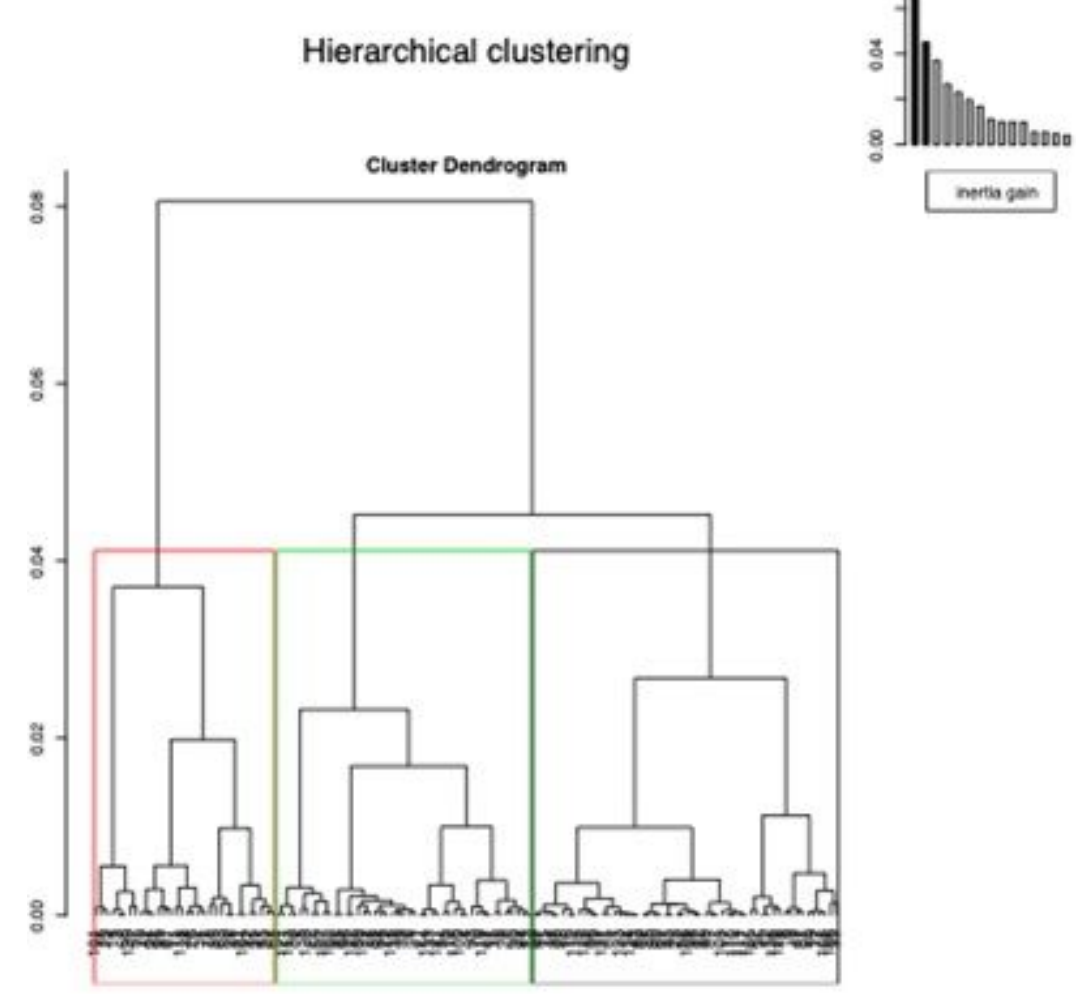

Figure 2

A cluster dendrogram summarized from a hierarchical ascending classification

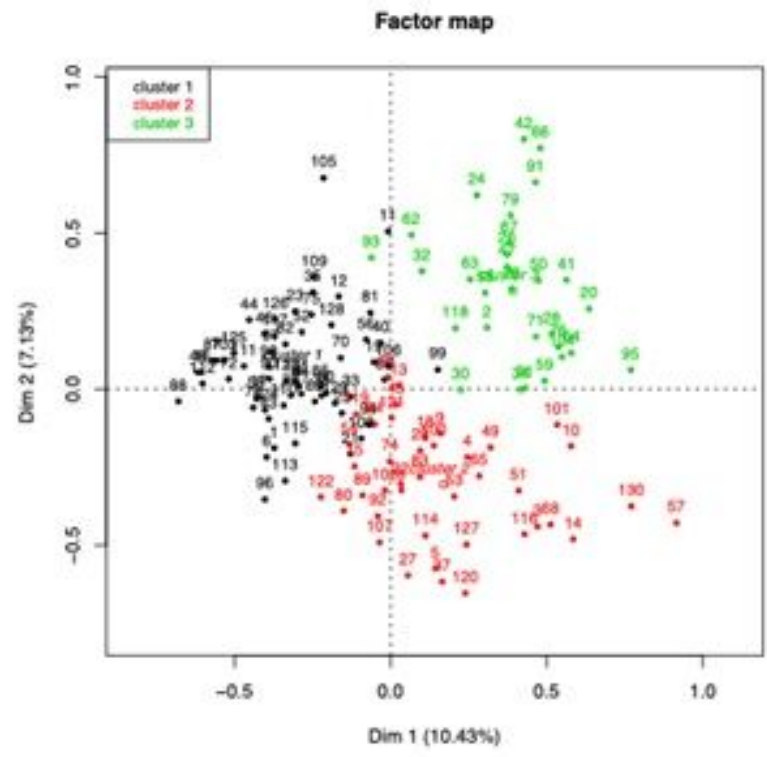

Figure 3

HCPC - factor map 


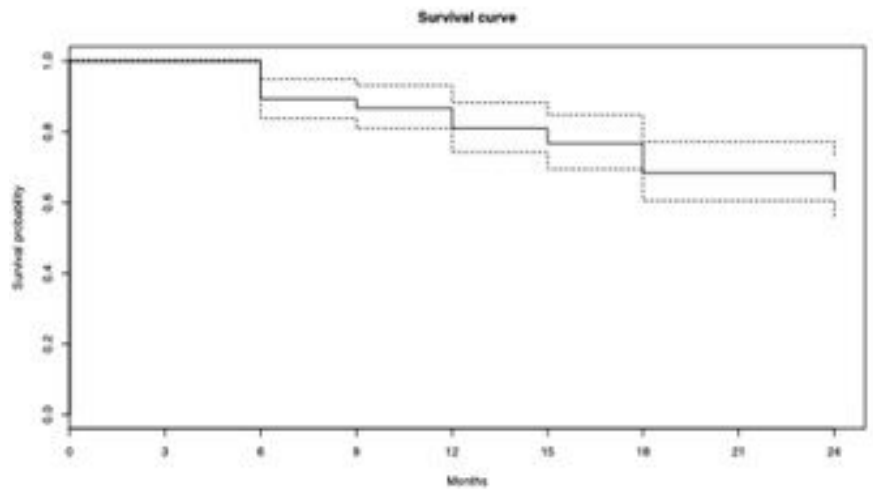

Figure 4

Overall survival curve of the cohort

\section{Supplementary Files}

This is a list of supplementary files associated with this preprint. Click to download.

- Englishtranslationquestionnaire.docx

- APPENDIX1.docx 